\title{
Recurrent focal segmental glomerulosclerosis after kidney transplantation
}

\author{
Rebecca Trachtman • Simranjeet S. Sran • \\ Howard Trachtman
}

Received: 29 December 2014 / Revised: 22 January 2015 / Accepted: 28 January 2015 / Published online: 19 February 2015

(C) IPNA 2015

\begin{abstract}
Focal segmental glomerulosclerosis (FSGS) is an important cause of glomerular disease in children and adolescents and nearly $50 \%$ of affected patients will progress to endstage kidney disease over a 5 to 10 -year period. Unfortunately, there is no established treatment for disease in the native kidney. Moreover, up to $55 \%$ of patients develop recurrent disease after receiving a kidney transplant, with a substantially higher risk in patients who have already experienced recurrent disease in a prior transplant. A number of clinical and laboratory factors have been identified as risk factors for this complication. In addition, new investigations into podocyte biology and circulating permeability factors have shed light on the cause of recurrent the disease. While a number of novel therapeutic agents have been applied in the management of this problem, there still is no proven treatment. In this review, we summarize recent advances in the epidemiology, pathophysiology, and treatment of recurrent FSGS in pediatric patients who have received a kidney transplant.
\end{abstract}

Keywords Focal segmental glomerulosclerosis - Recurrent disease $\cdot$ Kidney transplant $\cdot$ Genetics $\cdot$ Circulating factors . Plasmapheresis $\cdot$ Rituximab

\section{Introduction}

Primary focal segmental glomerulosclerosis (FSGS) is an increasingly common cause of end-stage kidney disease (ESKD). The incidence of this glomerulopathy is rising in children and adults and the disorder accounts for up to $10 \%$

R. Trachtman $\cdot$ S. S. Sran $\cdot$ H. Trachtman $(\bowtie)$

Division of Pediatric Nephrology, NYU Langone Medical Center, CTSI, Room \#733 227 E 30th Street, New York, NY 10016, USA e-mail: howard.trachtman@nyumc.org of patients of all ages who require renal replacement therapy [1]. Although kidney transplantation is the preferred approach to the treatment of ESKD, children with FSGS deserve special attention because there is a risk of recurrent disease and loss of the allograft. Although the risk is not high enough to contraindicate the procedure in patients with FSGS who are being evaluated for their first transplant, the likelihood of recurrence rises substantially in those who developed FSGS after the first procedure. In many cases, there is a reluctance to offer a second or third allograft to these unfortunate patients and they may be consigned to a life on maintenance dialysis. This observation underscores the need to improve our understanding of the pathophysiology of recurrent FSGS and develop new therapies to treat this serious complication in transplantation. There have been several excellent reviews on this topic that have been published recently [2]. In this article, we provide an updated summary of material on the epidemiology and management of recurrent FSGS that is relevant to pediatric patients with special emphasis on publications that have appeared in the last 10 years.

\section{Epidemiology}

Overall incidence The diagnosis of recurrent FSGS is usually based on the detection of nephrotic-range proteinuria in a patient that previously had a normal urinalysis after transplantation. There are cases of immediate recurrence of FSGS in which the child develops heavy proteinuria immediately post-transplantation without ever having a normal urinalysis. Although there can be biopsy findings consistent with the primary disease, the renal histopathology early in the course of recurrent FSGS may show only diffuse effacement of podocyte foot processes without the classical segmental sclerosis of glomeruli [3]. This may reflect the rapid onset of disease post-transplantation as opposed to more prolonged 
prodromal phase in native kidneys. Newer tissue markers are being identified to characterize recurrent FSGS including enhanced immunohistochemical staining for CD44 in podocytes, a biomarker of epithelial cell activation [4].

As depicted in Table 1, recent studies place the incidence of recurrent FSGS in the range of 6-55\%, with large variation between individual case series. However, in two studies that included only pediatric patients or provided separate data for children, the overall incidence was reported to be 43 and $55 \%[5,6]$. The review by Huang et al. [7] represents one of the largest reports regarding recurrent FSGS and described a much lower incidence of recurrence FSGS compared to other studies $(6 \%)$. It is unclear why the results of this study differ from nearly all other reports and may relate to the duration of the follow-up observation period. In addition, the stringency of the criteria used to make the diagnosis of FSGS in the native kidneys and recurrent disease in the allograft can alter the interpretation of the data. The authors acknowledge that detailed information about clinical and laboratory findings prior to transplant is not available for patients in the database that was used [7]. Hickson et al. [5] provided data for the incidence of recurrent disease for both a clinically based diagnosis of primary FSGS compared to biopsy-proven diagnosis and found the incidence to increase drastically from 55 to $75 \%$ [3]. The majority of studies reported an incidence closer to $25 \%$; however, these included pediatric and/or adult patients [8-11]. Trend analysis of data compiled by the United Network for Organ Sharing (UNOS) over the period from 1988-2008 showed an increase in cases of recurrent FSGS by $5.8 \%$ per year [12]. Maas et al. [13] have recently reported that recurrent disease only occurs in patients with idiopathic or primary FSGS (28 out of $66,42 \%$ ) and not in those with genetic or secondary causes of the glomerular disease. In this case series, a lower serum albumin concentration, a higher glomerular filtration rate (GFR), and acute rejection episodes were associated with a higher risk of recurrent FSGS. HLA mismatching is not a risk factor for recurrent FSGS [14].

Incidence - effect of age and gender Younger ages of the transplant recipient and rapid progression to ESKD necessitating kidney transplantation have been associated with increased recurrence [15]. All three studies with data regarding patient age that are presented in Table 1 are consistent with this trend, though the age range varies from study to study. Whereas prior studies compared incidence above and below a single age, Huang et al. [7] provide data for those with an age less than 12, from 13-17, and those older than 18, which follows the previously reported trend of an inverse relationship between patient age and likelihood of recurrence [7]. Three studies report data regarding gender and all found an increased incidence in females. Sener et al. [10] found a statistically significant difference with only one male compared to $50 \%$ of females having recurrent FSGS. The gender

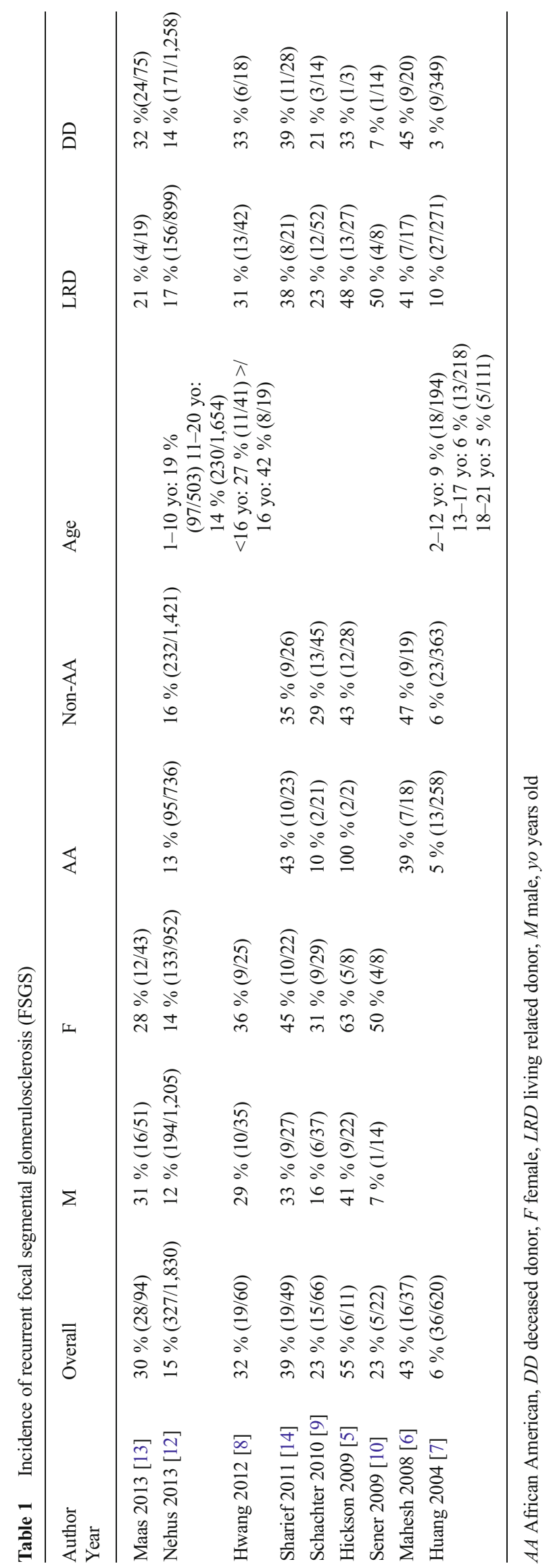


difference in the other two studies is not as striking, but they still report a 29 and $41 \%$ incidence in males and a 36 and $63 \%$ incidence in females [5, 8]. Hwang et al. [8] provide data for the gender of the donor and found a comparable incidence of $36 \%$ with a female donor versus $29 \%$ with a male donor. In a recent analysis of data from UNOS over the period 19882008 that included 2,157 pediatric kidney transplant recipients (age 1-20 years), young age was associated with an increased risk of recurrent FSGS [12].

Incidence-effect of recipient race African Americans show a lower incidence of recurrence compared to other races/ethnicities, namely, Caucasian, Hispanic, and Asians [6, 7, 9]. This is supported by nearly all studies summarized in Table 1 that include data on race/ethnicity. A heightened risk of recurrence in white children was also documented in a recent review of UNOS data over the 20-year period of 1988-2008 [12]. The report by Hickson et al. [5] is discordant. However, only two African Americans who required a kidney transplant secondary to FSGS were included in that study. The incidence rate for non-African Americans patients ranged from 25 to $43 \%$. This is at variance with the study of Huang et al. [7], which reported low rates of recurrent FSGS for nearly all groups. This study did describe an increased incidence in nonAfrican American patients.

Incidence-living-related versus deceased-donor transplant A multivariate analysis of data from UNOS from 1988 to 2008 failed to identify living-related donation as an independent risk factor for recurrent FSGS post-kidney transplantation [12].

Outcomes Recurrent FSGS can lead to early graft failure. In addition, it can spontaneously resolve without treatment. In the series of patients reported by Schachter et al. [9], recurrent FSGS increased the occurrence of death or ESKD from 12 to $27 \%$. Similarly, in a review of 2,687 adolescents with a kidney transplant enrolled in the North American Pediatric Renal Transplant Collaborative Study (NAPRTCS) database between 1987 and 2001, of whom 338 had primary FSGS, recurrent FSGS accounted for $15 \%$ of all graft failures $(17 \%$ in recipients of living related donor kidneys and $14 \%$ in recipients of deceased donor kidneys) [16]. Recurrent FSGS resulted in a loss of the expected living-donor graft survival advantage [16]. In contrast, Sener et al. [10] found no adverse effect of recurrent disease on allograft survival in patients with FSGS. A similar finding was also reported by Jungraithmayr in a series of 86 pediatric patients [11]. Thus, although the short-term course may be impacted by recurrent FSGS, this complication should be treated aggressively because it is not uniformly associated with adverse long-term outcomes.

\section{Pathogenesis}

Cases of primary FSGS can be hereditary or truly idiopathic in nature. The cause of the primary disease greatly impacts on the likelihood of recurrent disease after transplant.

Genetic factors-NPHS2 (podocin) Many genes have been found to play a role in hereditary FSGS. Using nextgeneration sequencing to test for all known loci, nearly $30 \%$ of children with steroid-resistant nephrotic syndrome and FSGS have a genetic cause for their disease [17]. Typically, patients with hereditary forms of disease exhibit significantly lower rates of recurrence compared to those with non-genetic primary disease. In fact, in some series, none of the patients with FSGS who had a causative genetic mutation responded to immunosuppressive treatment for disease in their native kidney but had minimal likelihood of recurrence in the allograft [18].

The gene coding for podocin, NPHS2, located on chromosome 1q25-31, has been the focus of many studies of recurrent FSGS because it is one of the most common genetic causes of primary disease $[16,17]$. Podocin is a slit-diaphragm protein that interacts with nephrin $[19,20]$. Patients who are homozygous for a mutation represent the most common genetic cause of familial autosomal recessive steroid-resistant nephrotic syndrome (SRNS). These patients rapidly progress to ESKD but have a very low incidence of recurrent disease. Jungraithmayr et al. [21] found no recurrence of disease after transplant in patients homozygous or compound heterozygous for the NPHS2 mutation, compared to recurrence in nearly half of all patients without the mutation. This is consistent with reports published by Weber et al. [22] and Ruff et al. [23]. Bertelli et al. [24] found no difference between those with or without mutations but failed to separate patients who were homozygous for podocin mutations from those who were heterozygous in their analysis. Only two patients out of 14 who were homozygous had recurrent disease. It has been hypothesized that the homozygous patients who do develop recurrent FSGS have autoantibodies against non-mutated podocin; however, to date, these antibodies have not been detected in the circulation. NPHS2 testing may play a valuable role predicting recurrence of disease, especially distinguishing between homozygotes from heterozygotes and those without mutations.

It is still unclear what impact a single NPHS2 mutation has on recurrence of FSGS after transplantation. Weber et al. [22] concluded that patients with two mutations presented with early onset disease and low recurrence rate $(3 \%)$ and those with heterozygous mutations presented with more mild, lateonset disease with an increased likelihood of recurrence (34\%). These patients may have another mutation, such as in Nephrin (NPHS1) which could be just one of many potential modifiers changing the disease course and influencing the 
risk of recurrence, which requires further study. The R229Q polymorphism may be involved in the pathogenesis of FSGS but does not appear to be useful in predicting recurrent disease [25]. In general, patients with FSGS and a causative genetic mutation have minimal risk of recurrent disease. This distinction can be made on clinical grounds. Thus, in a recent study, patients with FSGS who had initial steroid responsiveness that evolved to secondary steroid resistance had a high risk of recurrent disease. In contrast, patients with initial steroid resistance were more likely to have a genetic cause of FSGS and a significantly lower likelihood of developing recurrence posttransplant [26].

Circulating permeability factor-suPAR A circulating permeability factor(s) has long been implicated in the development of primary FSGS [27]. Alternatively, the causative insult leading to glomerular dysfunction and proteinuria in patients with FSGS may be a factor which inhibits the circulating permeability factor and which is absent in patients who exhibit primary disease. This allows the circulating permeability factor to act unopposed and cause damage to the glomerular basement membrane (GBM).

Some have hypothesized that these circulating factors also cause post-transplant recurrence of FSGS. The detection of podocyte foot process effacement within minutes of donor kidney reperfusion in patients who develop recurrent FSGS is strong evidence in support of a circulating factor [28]. Shaloub originally postulated that the circulating permeability factor(s) would be a T cell-derived mediators which is toxic to the GBM [29]. Further biochemical characterization of this putative permeability factor suggests that the molecule is anionic, has a low molecular weight, and interacts with protein $\mathrm{A}$ and galactose [30-32]. It has been hypothesized that this factor may exert its influence by interacting with nephrin and podocin, altering phosphorylation in podocytes, altering serine proteases, inducing integrin-like kinase activity, and inhibiting synthesis of NO [32-36].

Much recent work has identified suPAR, soluble urokinase-like plasminogen activator receptor, as a circulating factor that may cause FSGS. Wei et al. [37] found that suPAR is elevated in nearly two-thirds of patients with primary FSGS and that a higher pre-transplant level correlates with increased risk of recurrence. suPAR-mediated activation of $\beta 3$ integrin is the putative mechanism of action of this molecule. A follow-up study reported elevated serum suPAR levels in 55 and $84 \%$ of patients with primary FSGS in two welldescribed cohorts compared to $6 \%$ of controls [38]. Elevated levels of suPAR were noted in patients with an NPHS2 mutation. In addition, lower levels were associated with male sex and increased estimated GFR [38]. Findings in other cohorts have raised questions about the role of suPAR in the pathogenesis of proteinuria, its ability to discriminate FSGS from other forms of primary glomerular disease, and its predictive value in identifying recurrent disease post-transplant [39-41]. Additional studies are needed to determine the role of this specific molecule in primary FSGS in native kidneys and recurrent disease in renal allografts.

High suPAR levels in the circulation were linked to recurrent FSGS post-transplantation [37]. Podocyte foot process effacement, the initial histological sign of recurrent FSGS, correlates with circulating suPAR levels at the time of diagnosis [42]. Enhanced urinary excretion of suPAR may be more predictive of recurrent FSGS than an elevated serum concentration of the mediator [43]. Finally, suPAR may interact with other molecules to trigger proteinuria and recurrent FSGS. In a study of 64 patients with primary and secondary FSGS, a panel of seven antibodies had a $92 \%$ accuracy in predicting recurrent disease and of the seven, anti-CD40 antibody had the highest correlation with recurrent disease. While suPAR alone did not cause proteinuria in normal mice, coadministration of suPAR and anti-CD40 antibody provoked podocyte injury and proteinuria [44]. This important observation suggests that circulating factors like suPAR may be prominent contributors to a multi-hit process that culminates in recurrent FSGS.

\section{Treatment}

Standard medical care Conservative regimens for the treatment of recurrent FSGS center on administration of angiotensin-converting enzyme inhibitors and/or angiotensin receptor blockers alone or in combination with calcineurin inhibitors. Use of these agents in a fashion that is often applied to manage primary FSGS in the native kidney has not proven widely successful in recurrent FSGS in the transplant setting. As a result, there is interest in the use of other treatments that intensify immunosuppression, notably plasmapheresis and biological antibodies (e.g., rituximab), often coupled with pulse corticosteroids and calcineurin inhibitors. Recent reports indicate that up to $70 \%$ of pediatric patients with recurrent FSGS can achieve a complete remission and stabilization of kidney function for up to 10 years in response to a combination of cyclosporine and pulse intravenous methylprednisolone [45]. Drugs that interfere with the renin-angiotensin axis and a calcineurin inhibitor may be added to the therapeutic regimen in patients who fail to respond adequately to plasma exchange or rituximab.

Plasmapheresis Plasma-based treatments, primarily plasmapheresis, have been used as a first-line treatment for FSGS and for recurrent FSGS after transplantation for nearly 20 years [5, 46-59]. The results of select studies performed since the year 2000 with larger numbers of patients are summarized in Table 2. 
Table 2 Treatment of recurrent focal segmental glomerulosclerosis (FSGS): Efficacy of plasmapheresis

\begin{tabular}{lllllllllll}
\hline $\begin{array}{l}\text { Author } \\
\text { Year }\end{array}$ & $N$ & P/IM & Age & PT type & \# PT Rx & Other Rx & LRD/DD & CR/PR/NR & REL & SAE \\
\hline Ohta 2001 [50] & 15 & P & 4.7 & PP & $2-3$ & S,A,M.CSA,T & 13,2 & $10 / 0 / 5$ & 0 & 0 \\
Otsubo 2004 [53] & 20 & P/IM & 23 & PP & $1-5$ & S,A,M, CSA, MMF & NA & $13 / 0 / 7$ & NA & 0 \\
Hickson 2009 [5] & 7 & P/IM & 25 & PP & NA & S, T, SIR & 6 (LUD) & $4 / 1 / 2$ & 2 CR, 1 PR & 0 \\
Gonzalez 2011 [59] & 17 & P & NA & PP & $1-10$ & S, CSA, T, MMF & NA & $8 / 0 / 9$ & 2 CR & 0 \\
\hline
\end{tabular}

$A$, azathioprine, $C R$ complete remission, $C S A$ cyclosporine, $D D$ deceased donor, $I M$ internal medicine, $L R D$ living related donor, $L U D$ living unrelated donor, $M$ mizoribine, $M M F$ mycophenolate mofetil, $N A$ not available, $N R$ no remission, $P$ pediatric, $P P$ plasmapheresis, $P R$ partial remission, $P T$ plasma therapy, $R E L$ relapse, $R x$ treatment, $S$ steroids, $S A E$ serious adverse event, $S I R$ sirolimus, $T$ tacrolimus

Although plasmapheresis is the most established treatment for recurrent FSGS, there are few randomized controlled studies of its use and most reports have been retrospective reviews of experience at a single center, usually without control subjects. Despite this, plasmapheresis continues to be considered the standard of care.

When reviewing results of the more recent literature, it is clear that plasmapheresis is a useful therapy in that it is safe with minimal side effects and no serious adverse events reported. Based on published reports, plasmapheresis appears to be moderately effective as prophylaxis against FSGS recurrence prior to renal transplantation and as treatment of recurrence after transplantation, with a response rate of approximately $60 \%$. In general, younger patients may be more responsive to therapy with plasmapheresis. It can be used as the sole therapeutic modality with good results. Straatman et al. [60] documented that plasmapheresis without concomitant use of immunosuppressive drugs was effective in treating seven out of 29 patients with FSGS who received a kidney transplant and who developed recurrent disease. However, it is important to recognize that in most series, there is a need for administration of additional treatment modalities to achieve remission or significant reduction in proteinuria, given that approximately $40 \%$ of people affected do not respond to therapy with plasmapheresis as the sole therapeutic intervention.

A specific type of pheresis therapy, LDL apheresis with an absorptive column, which has been used to treat familial hypercholesterolemia, has been shown to be effective in a small series of patients with FSGS [61]. This procedure is FDA approved for the management of primary and recurrent FSGS. Further studies are warranted to determine the efficacy of this therapeutic modality.

Rituximab In recent years, rituximab has been increasingly utilized as a therapy of last resort in cases of recurrent FSGS that are refractory to therapy with the more established treatment options. Since the year 2000, numerous case reports and small studies of the efficacy of rituximab in treating FSGS have been published [62-78]. The larger case series are summarized in Table 3. Unfortunately, there are no prospective or randomized case-controlled studies of rituximab for recurrent FSGS. The literature to date provides evidence that rituximab is effective in treating recurrent FSGS. Excluding all case reports that may have a bias in favor of publication of good outcomes, studies show a $79 \%$ response rate of recurrent FSGS to rituximab. As expected, the response rate increases to $85 \%$ when case reports are included. Pre-clinical studies demonstrate that rituximab binds directly to sphingomyelin phosphodiesterase acid-like 3b (SMPDL-3b) protein and regulates acid sphingomyelinase activity in the podocyte. Rituximab treatment in 27 patients with recurrent FSGS was associated with lower incidence of post-transplant proteinuria and stabilization of glomerular filtration rate, an effect that was associated with prevention of SMPDL-3b sphingomyelinase down-regulation in podocytes [79]. These exciting findings provide strong rationale for this therapeutic intervention for recurrent FSGS.

The published literature suggests that there is a consensus regarding the appropriate use of rituximab, evidenced by the overlapping dosing regimens in the reports. However, the question of rituximab dosing should be considered open, especially in view of a recent case report documenting effective treatment of recurrent FSGS with a single 100-mg dose of the antibody [80]. An additional concern with the use of rituximab is the side-effect profile. Only one study reported significant adverse effects from rituximab. While the effects reported were serious, only $7.5 \%$ of patients treated had an adverse reaction, and all of these were within the same study [78].

Based on the data from existing studies, it appears that rituximab is a useful treatment for recurrent FSGS; however, randomized case-controlled studies are still needed to strengthen these results. It is important to consider the impact of selection and publication bias in the literature reported above. Most of the patients described in the literature have usually been treated with multiple different medications, making it difficult to parse out the treatment effects of specific drugs, including rituximab. These biases weaken conclusions that can be drawn from the results of these studies and further investigation is required in more standardized and rigorous 
Table 3 Treatment of recurrent focal segmental glomerulosclerosis (FSGS): Efficacy of rituximab

\begin{tabular}{|c|c|c|c|c|c|c|c|c|}
\hline $\begin{array}{l}\text { Author } \\
\text { Year }\end{array}$ & $N$ & $\mathrm{P} / \mathrm{IM}$ & Age Yr & Dose & Other Rx & $\mathrm{CR} / \mathrm{PR} / \mathrm{NR}$ & REL & SAE \\
\hline Benz 2004 [62] & 1 & $\mathrm{P}$ & 16 & $375 \mathrm{mg} / \mathrm{m}^{2} \mathrm{X} 4$ & $\mathrm{~S}, \mathrm{C}, \mathrm{CsA}, \mathrm{T}$ & & & NA \\
\hline Nozu 2005 [63] & 1 & $\mathrm{P}$ & 12 & $375 \mathrm{mg} / \mathrm{m}^{2} \mathrm{X} 4$ & NA & & & NA \\
\hline Pescovitz 2006 [64] & 1 & $\mathrm{P}$ & 7 & $375 \mathrm{mg} / \mathrm{m}^{2} \mathrm{X} 6$ & $\mathrm{~S}$ & & & NA \\
\hline Hristea 2007 [65] & 1 & $\mathrm{IM}$ & 22 & $375 \mathrm{mg} / \mathrm{m}^{2} \mathrm{X} 2$ & PT,C & & & NA \\
\hline Kamar 2007 [66] & 1 & NA & NA & $375 \mathrm{mg} / \mathrm{m}^{2} \mathrm{X} 2$ & PT,C & & & NA \\
\hline Grossman 2007 [67] & 1 & $\mathrm{IM}$ & 48 & $375 \mathrm{mg} / \mathrm{m}^{2} \mathrm{X} 2$ & PT,S,MMF,T & PR & 0 & 0 \\
\hline Meyer 2007 [68] & 1 & $\mathrm{IM}$ & 29 & $375 \mathrm{mg} / \mathrm{m}^{2} \mathrm{X} 3$ & PT,S,MMF,T & PR & 0 & 0 \\
\hline El-Firjani 2008 [69] & 1 & $\mathrm{IM}$ & 46 & $375 \mathrm{mg} / \mathrm{m}^{2} \mathrm{X} 6$ & PT & & & 0 \\
\hline Yabu 2008 [70] & 4 & $\mathrm{IM}$ & $41-47$ & $375 \mathrm{mg} / \mathrm{m}^{2} \mathrm{X} 6$ & PT,MMF & $0 / 0 / 4$ & NA & 0 \\
\hline Hickson 2009 [5] & 4 & $\mathrm{P}$ & $5-19$ & $375 \mathrm{mg} / \mathrm{m}^{2} \mathrm{X} 2-4$ & PT,S,C,CSA,T, MMF,B & & 4 & 0 \\
\hline Shimizu 2010 [71] & 1 & $\mathrm{P}$ & 20 & $375 \mathrm{mg} / \mathrm{m}^{2} \mathrm{X} 2$ & LCAP & & No & 0 \\
\hline Grenda 2011 [72] & 1 & $\mathrm{P}$ & 5 & $375 \mathrm{mg} / \mathrm{m}^{2} \mathrm{X} 4$ & PT,S,CSA & $\mathrm{CR}$ & 0 & 0 \\
\hline Sethna 2011 [73] & 4 & $\mathrm{P}$ & $13-18$ & $375 \mathrm{mg} / \mathrm{m}^{2} \mathrm{X} 4$ & PT,S,C,CSA,MMF & $3 / 1 / 0$ & 2 & 0 \\
\hline Tsagalis 2011 [74] & 4 & $\mathrm{IM}$ & $21-48$ & $1000 \mathrm{mg} \mathrm{X} 2$ & C,PT,S,C,CSA,MMF & $2 / 2 / 0$ & 1 & 0 \\
\hline Okamoto 2011 [75] & 1 & $\mathrm{P}$ & 15 & $200 \mathrm{mg} \mathrm{X} 2$ & PT,S,T,M & PR & 0 & 0 \\
\hline Stewart 2011 [76] & 1 & $\mathrm{P}$ & 16 & $375 \mathrm{mg} / \mathrm{m}^{2} \mathrm{X} 4$ & PT,S,MMF,T,CSA & $\mathrm{CR}$ & 0 & 0 \\
\hline Audard 2012 [77] & 4 & $\mathrm{IM}$ & $28-43$ & $375 \mathrm{mg} / \mathrm{m}^{2} \mathrm{X} 1-2$ & S,MMF,T & $4 / 0 / 0$ & 0 & 0 \\
\hline Kumasi 2013 [78] & 8 & & NA & Amount NA X1-4 & PT & $2 / 4 / 2$ & 0 & Yes \\
\hline
\end{tabular}

$B$ basiliximab, $C$ cyclophosphamide, $C R$ complete remission, $C S A$ cyclosporine, $I M$ internal medicine, $L C A P$ lymphocytapheresis, $M$ mizolibine, $M M F$ mycophenolate mofetil, $N A$ not, available, $N R$ no remission, $P$ pediatric, $P R$ partial remission, $P T$ plasma therapy, $R E L$ relapse, $S$ steroids, $S A E$ serious adverse event, $T$ tacrolimus

clinical protocols. Alternatively, it is conceivable that more severe, difficult-to-treat cases were included in these studies, and results might be negatively skewed, underestimating the true treatment potential of rituximab.

Novel treatments Abatacept (cytotoxic T-lymphocyteassociated antigen 4-immunoglobulin fusion protein [CTLA4-Ig]), a co-stimulatory inhibitor that targets B7-1 (CD80), is the most recent addition to the available options to treat patients with recurrent FSGS. There have been isolated case reports documenting resolution of recurrent FSGS in patients who received abatacept in doses that have been utilized for the treatment of systemic lupus erythematosus [81]. However, this observation has not been replicated by other investigators who failed to achieve permanent remission in patients with recurrent FSGS [82]. Differences in response to abatacept may be related to variable expression of B7-1 in the glomerulus. However, because abatacept is a safe drug that has been used for other indications, it will be essential to evaluate the efficacy of this antibody for the treatment of recurrent FSGS in a randomized clinical trial.

Finally, there have been two recent reports in which infusion of allogeneic mesenchymal stem cells was used to successfully stabilize kidney function in children with recurrent FSGS or prevent this complication [83, 84]. In view of the high cost and potential serious adverse events associated with this approach to treat recurrent FSGS, more investigation is warranted to provide rational for stem cell-based treatments.

\section{Future directions}

One key step in improving the diagnosis and treatment of recurrent FSGS will be to better define the incidence and epidemiology of this complication. Nearly all of the current data are derived from single-center retrospective studies. One approach to enhance the quality of the information about recurrent FSGS would be to establish centralized registries that would mandate reporting of this serious adverse event and prospective monitoring of outcomes. If this were integrated with databases that record demographic and clinical data, it would facilitate identification of trends in the occurrence of this complication and factors associated with a higher likelihood of recurrence.

Early diagnosis of recurrent FSGS would assist in prompt initiation of therapy and potentially improve outcomes. Although transplant kidney biopsies are often performed to confirm the diagnosis, the procedure is invasive and is associated with significant risk. Moreover, the histopathological findings may be equivocal and fail to clarify the diagnosis. Although efforts are ongoing to identify histopathological markers with 
greater sensitivity and specificity for recurrent FSGS, this line of investigation would not eliminate the need for performance of a biopsy. Thus, it would be preferable to develop non-invasive urinary or serum tests that could expedite the diagnosis of recurrent disease. Recent reports have documented that a urinary-cell mRNA profile can improve the diagnosis of acute cellular rejection in kidney transplant recipients [85]. Improved understanding of the pathophysiology of recurrent FSGS may enable the development of a urine test that would be designed to specifically establish the diagnosis of recurrent disease in patients with primary FSGS who receive a kidney transplant.

Because of the limited armamentarium of drugs that are effective in the treatment of FSGS in the native kidney, it is no surprise that there are few options in patients with recurrent disease. It is likely that improvements in the treatment of recurrent disease will follow in the footsteps of advances in the management of the disease in the native kidney. The potential role of suPAR in the pathogenesis of both types of FSGS represents a viable target for therapeutic intervention. Protein A immunoadsorption columns are ineffective in reducing suPAR levels in patients with recurrent FSGS and therefore new modalities will be needed to accomplish this if suPAR is confirmed to play a central role in this complication [86].

In view of the primary role of the podocyte in the appearance of proteinuria in patients with primary FSGS, it is imperative to clarify the molecular biology of podocyte dysfunction in patients with recurrent FSGS in the expectation that this will allow novel agents to be developed that reverse diseaseassociated abnormalities. However, additional work will be required to ascertain if agents are effective for the control of FSGS in the native and transplanted kidney. For example, the impact of genetic mutations in podocyte proteins and other modifier genes will need to be carefully assessed. It is clear that multicenter clinical trials will be required to assess the efficacy of potential treatments and it is hoped that a selfsustaining network of high-quality clinical sites can be established and maintained in order to foster timely performance of these urgently needed studies.

Acknowledgments This work was supported in part by a grant from the NIH-NIDDK (DK70341)

\section{Questions (Answers are provided following the reference list)}

1. Which of the following clinical features has been associated with an increased risk of recurrent FSGS after kidney transplantation?
a. Young age
b. HLA mismatch
c. Male gender
d. Black race

2. Which of the following factors is associated with a lower likelihood of recurrent FSGS post transplantation?
a. Primary steroid resistance
b. Secondary steroid resistance
c. Prior use of calcineurin inhibitors
d. Prior use of rituximab

3. The reported epidemiology of recurrent FSGS is MOST affected by which of the following?
a. Underreporting by patients
b. Lack of standardized definition of recurrent FSGS
c. Lack of graft biopsies for accurate diagnosis
d. Underreporting by providers

4. In patients with recurrent FSGS, response to rituximab has been associated with expression of which of the following proteins?
a. Podocin
b. $\mathrm{CD} 20$
c. B7-1
d. sphingomyelin phosphodiesterase acid-like $3 \mathrm{~b}$

\section{References}

1. Kiffel J, Rahimzada Y, Trachtman H (2011) Focal segmental glomerulosclerosis and chronic kidney disease in pediatric patients. Adv Chronic Kidney Dis 18(5):332-338

2. Cravedi P, Kopp JB, Remuzzi G (2013) Recent progress in the pathophysiology and treatment of FSGS recurrence. Am J Transplant 13(2):266-274

3. Kowalewska J (2013) Pathology of recurrent diseases in kidney allografts: membranous nephropathy and focal segmental glomerulosclerosis. Curr Opin Organ Transplant 18(3):313-318

4. Fatima H, Moeller MJ, Smeets B, Yang HC, D'Agati VD, Alpers CE, Fogo AB (2012) Parietal epithelial cell activation marker in early recurrence of FSGS in the transplant. Clin J Am Soc Nephrol 7(11):1852-1858

5. Hickson LJ, Gera M, Amer H, Iqbal CW, Moore TB, Milliner DS, Cosio FG, Larson TS, Stegall MD, Ishitani MB, Gloor JM, Griffin MD (2009) Kidney transplantation for primary focal segmental glomerulosclerosis: outcomes and response to therapy for recurrence. Transplantation 87(8):1232-1239

6. Mahesh S, Del Rio M, Feuerstein D, Greenstein S, Schechner R, Tellis V, Kaskel F (2008) Demographics and response to therapeutic plasma exchange in pediatric renal transplantation for focal glomerulosclerosis: a single center experience. Pediatr Transplant 12(6):682-688

7. Huang K, Ferris ME, Andreoni KA, Gipson DS (2004) The differential effect of race among pediatric kidney transplant recipients with focal segmental glomerulosclerosis. Am J Kidney Dis 43(6):10821090

8. Hwang JH, Han SS, Huh W, Park SK, Joo DJ, Kim MS, Kim YS, Min SI, Ha J, Kim SJ, Kim S, Kim YS (2012) Outcome of kidney allograft in patients with adulthood-onset focal segmental glomerulosclerosis: comparison with childhood-onset FSGS. Nephrol Dial Transplant 27(6):2559-2565

9. Schachter ME, Monahan M, Radhakrishnan J, Crew J, Pollak M, Ratner L, Valeri AM, Stokes MB, Appel GB (2010) Recurrent focal segmental glomerulosclerosis in the renal allograft: single center 
experience in the era of modern immunosuppression. Clin Nephrol 74(3):173-181

10. Sener A, Bella AJ, Nguan C, Luke PP, House AA (2009) Focal segmental glomerular sclerosis in renal transplant recipients: predicting early disease recurrence may prolong allograft function. Clin Transplant 23(1):96-100

11. Jungraithmayr TC, Bulla M, Dippell J, Greiner C, Griebel M, Leichter HE, Plank C, Tönshoff B, Weber LT, Zimmerhackl LB, German MMF Study Group (2005) Primary focal segmental glomerulosclerosis-long-term outcome after pediatric renal transplantation. Pediatr Transplant 9(2):226-231

12. Nehus EJ, Goebel JW, Succop PS, Abraham EC (2013) Focal segmental glomerulosclerosis in children: multivariate analysis indicates that donor type does not alter recurrence risk. Transplantation 96(6): 550-554

13. Maas RJ, Deegens JK, van den Brand JA, Cornelissen EA, Wetzels JF (2013) A retrospective study of focal segmental glomerulosclerosis: clinical criteria can identify patients at high risk for recurrent disease after first renal transplantation. BMC Nephrol $14: 47$

14. Sharief S, Mahesh S, Del Rio M, Telis V, Woroniecki RP (2011) Recurrent focal segmental glomerulosclerosis in renal allograft recipients: role of human leukocyte antigen mismatching and other clinical variables. Int J Nephrol 2011:506805. doi:10.4061/2011/506805

15. Ponticelli C (2010) Recurrence of focal segmental glomerular sclerosis (FSGS) after renal transplantation. Nephrol Dial Transplant 25(1):25-31

16. Baum MA, Ho M, Stablein D, Alexander SR, North American Pediatric Renal Transplant Cooperative Study (2002) Outcome of renal transplantation in adolescents with focal segmental glomerulosclerosis. Pediatr Transplant 6(6):488-492

17. Sadowski CE, Lovric S, Ashraf S, Pabst WL, Gee HY, Kohl S, Engelmann S, Vega-Warner V, Fang H, Halbritter J, Somers MJ, Tan W, Shril S, Fessi I, Lifton RP, Bockenhauer D, El-Desoky S, Kari JA, Zenker M, Kemper MJ, Mueller D, Fathy HM, Soliman NA, the SRNS Study Group, Hildebrandt F (2014) A single-gene cause in $29.5 \%$ of cases of steroid-resistant nephrotic syndrome. J Am Soc Nephrol. doi:10.1681/ASN.2014050489

18. Giglio S, Provenzano A, Mazzinghi B, Becherucci F, Giunti L, Sansavini G, Ravaglia F, Roperto RM, Farsetti S, Benetti E, Rotondi M, Murer L, Lazzeri E, Lasagni L, Materassi M, Romagnani P (2014) Heterogeneous genetic alterations in sporadic nephrotic syndrome associate with resistance to immunosuppression. J Am Soc Nephrol 26:230-236

19. Boute N, Gribouval O, Roselli S, Benessy F, Lee H, Fuchshuber A, Dahan K, Gubler MC, Niaudet P, Antignac C (2000) NPHS2, encoding the glomerular protein podocin, is mutated in autosomal recessive steroid-resistant nephrotic syndrome. Nat Genet 24(4): 349-354

20. McCarthy HJ, Bierzynska A, Wherlock M, Ognjanovic M, Kerecuk L, Hegde S, Feather S, Gilbert RD, Krischock L, Jones C, Sinha MD, Webb NJ, Christian M, Williams MM, Marks S, Koziell A, Welsh GI, Saleem MA, RADAR the UK SRNS Study Group (2013) Simultaneous sequencing of 24 genes associated with steroidresistant nephrotic syndrome. Clin J Am Soc Nephrol 8(4):637-648

21. Jungraithmayr TC, Hofer K, Cochat P, Chernin G, Cortina G, Fargue S, Grimm P, Knueppel T, Kowarsch A, Neuhaus T, Pagel P, Pfeiffer KP, Schäfer F, Schönermarck U, Seeman T, Toenshoff B, Weber S, Winn MP, Zschocke J, Zimmerhackl LB (2011) Screening for NPHS2 mutations may help predict FSGS recurrence after transplantation. J Am Soc Nephrol 22(3):579-585

22. Weber S, Gribouval O, Esquivel EL, Morinière V, Tête MJ, Legendre C, Niaudet P, Antignac C (2004) NPHS2 mutation analysis shows genetic heterogeneity of steroid-resistant nephrotic syndrome and low post-transplant recurrence. Kidney Int 66(2):571-579
23. Ruf RG, Lichtenberger A, Karle SM, Haas JP, Anacleto FE, Schultheiss M, Zalewski I, Imm A, Ruf EM, Mucha B, Bagga A, Neuhaus T, Fuchshuber A, Bakkaloglu A, Hildebrandt F, Arbeitsgemeinschaft Für Pädiatrische Nephrologie Study Group (2004) Patients with mutations in NPHS2 (podocin) do not respond to standard steroid treatment of nephrotic syndrome. J Am Soc Nephrol 15(3):722-732

24. Bertelli R, Ginevri F, Caridi G, Dagnino M, Sandrini S, Di Duca M, Emma F, Sanna-Cherchi S, Scolari F, Neri TM, Murer L, Massella L, Basile G, Rizzoni G, Perfumo F, Ghiggeri GM (2003) Recurrence of focal segmental glomerulosclerosis after renal transplantation in patients with mutations of podocin. Am J Kidney Dis 41(6):1314-1321

25. Mohey H, Thibaudin L, Laurent B, Berthoux F (2013) The podocin mutation R229Q and early recurrence (within the first year) of glomerular disease after renal transplantation. Ann Transplant 18:436442

26. Ding WY, Koziell A, McCarthy HJ, Bierzynska A, Bhagavatula MK, Dudley JA, Inward CD, Coward RJ, Tizard J, Reid C, Antignac C, Boyer O, Saleem MA (2014) Initial steroid sensitivity in children with steroid-resistant nephrotic syndrome predicts post-transplant recurrence. J Am Soc Nephrol 25(6):1342-1348

27. McCarthy ET, Sharma M, Savin VJ (2010) Circulating permeability factors in idiopathic nephrotic syndrome and focal segmental glomerulosclerosis. Clin J Am Soc Nephrol 5(11):2115-2121

28. Chang JW, Pardo V, Sageshima J, Chen L, Tsai HL, Reiser J, Wei C, Ciancio G, Burke GW 3rd, Fornoni A (2012) Podocyte foot process effacement in post-reperfusion allograft biopsies correlates with early recurrence of proteinuria in focal segmental glomerulosclerosis. Transplantation 93(12):1238-1244

29. Shalhoub RJ (1974) Pathogenesis of lipoid nephrosis: a disorder of Tcell function. Lancet 2(7880):556-560

30. Savin VJ, McCarthy ET, Sharma M (2003) Permeability factors in focal segmental glomerulosclerosis. Semin Nephrol 23(2):147-160

31. Sharma M, Sharma R, McCarthy ET, Savin VJ (2004) The focal segmental glomerulosclerosis permeability factor: biochemical characteristics and biological effects. Exp Biol Med (Maywood) 229(1): $85-98$

32. Savin VJ, McCarthy ET, Sharma R, Charba D, Sharma M (2008) Galactose binds to focal segmental glomerulosclerosis permeability factor and inhibits its activity. Transl Res 151(6):288-292

33. Schwartz MM (2000) The role of podocyte injury in the pathogenesis of focal segmental glomerulosclerosis. Ren Fail 22(6):663-684

34. Hattori M, Akioka Y, Chikamoto H, Kobayashi N, Tsuchiya K, Shimizu M, Kagami S, Tsukaguchi H (2008) Increase of integrinlinked kinase activity in cultured podocytes upon stimulation with plasma from patients with recurrent FSGS. Am J Transplant 8(7): $1550-1556$

35. Carraro M, Zennaro C, Artero M, Candiano G, Ghiggeri GM, Musante L, Sirch C, Bruschi M, Faccini L (2004) The effect of proteinase inhibitors on glomerular albumin permeability induced in vitro by serum from patients with idiopathic focal segmental glomerulosclerosis. Nephrol Dial Transplant 19(8):1969-1975

36. Trachtman H, Futterweit S, Singhal PC, Franki N, Sharma M, Sharma R, Savin V (1999) Circulating factor in patients with recurrent focal segmental glomerulosclerosis postrenal transplantation inhibits expression of inducible nitric oxide synthase and nitric oxide production by cultured rat mesangial cells. J Investig Med 47(3): $114-120$

37. Wei C, El Hindi S, Li J, Fornoni A, Goes N, Sageshima J, Maiguel D, Karumanchi SA, Yap HK, Saleem M, Zhang Q, Nikolic B, Chaudhuri A, Daftarian P, Salido E, Torres A, Salifu M, Sarwal MM, Schaefer F, Morath C, Schwenger V, Zeier M, Gupta V, Roth D, Rastaldi MP, Burke G, Ruiz P, Reiser J (2011) Circulating urokinase receptor as a cause of focal segmental glomerulosclerosis. Nat Med 17(8):952-960 
38. Wei C, Trachtman H, Li J, Dong C, Friedman AL, Gassman JJ, McMahan JL, Radeva M, Heil KM, Trautmann A, Anarat A, Emre S, Ghiggeri GM, Ozaltin F, Haffner D, Gipson DS, Kaskel F, Fischer DC, Schaefer F, Reiser J, PodoNet and FSGS CT Study Consortia (2012) Circulating suPAR in two cohorts of primary FSGS. J Am Soc Nephrol 23(12):2051-2059

39. Meijers B, Maas RJ, Sprangers B, Claes K, Poesen R, Bammens B, Naesens M, Deegens JK, Dietrich R, Storr M, Wetzels JF, Evenepoel P, Kuypers D (2014) The soluble urokinase receptor is not a clinical marker for focal segmental glomerulosclerosis. Kidney Int 85(3): 636-640

40. Sinha A, Bajpai J, Saini S, Bhatia D, Gupta A, Puraswani M, Dinda AK, Agarwal SK, Sopory S, Pandey RM, Hari P, Bagga A (2014) Serum-soluble urokinase receptor levels do not distinguish focal segmental glomerulosclerosis from other causes of nephrotic syndrome in children. Kidney Int 85(3):649-658

41. Spinale JM, Mariani LH, Kapoor S, Zhang J, Weyant R, Song PX, Wong HN, Troost JP, Gadegbeku CA, Gipson DS, Kretzler M, Nihalani D, Holzman LB (2014) A reassessment of soluble urokinase-type plasminogen activator receptor in glomerular disease. Kidney Int. doi:10.1038/ki.2014.346

42. Alachkar N, Wei C, Arend LJ, Jackson AM, Racusen LC, Fornoni A, Burke G, Rabb H, Kakkad K, Reiser J, Estrella MM (2013) Podocyte effacement closely links to suPAR levels at time of posttransplantation focal segmental glomerulosclerosis occurrence and improves with therapy. Transplantation 96(7):649-656

43. Franco Palacios CR, Lieske JC, Wadei HM, Rule AD, Fervenza FC, Voskoboev N, Garovic VD, Zand L, Stegall MD, Cosio FG, Amer H (2013) Urine but not serum soluble urokinase receptor (suPAR) may identify cases of recurrent FSGS in kidney transplant candidates. Transplantation 96(4):394-399

44. Delville M, Sigdel TK, Wei C, Li J, Hsieh SC, Fornoni A, Burke GW, Bruneval P, Naesens M, Jackson A, Alachkar N, Canaud G, Legendre C, Anglicheau D, Reiser J, Sarwal MM (2014) A circulating antibody panel for pretransplant prediction of FSGS recurrence after kidney transplantation. Sci Transl Med 6(256):256ra136

45. Shishido S, Satou H, Muramatsu M, Hamasaki Y, Ishikura K, Hataya H, Honda M, Asanuma H, Aikawa A (2013) Combination of pulse methylprednisolone infusions with cyclosporine-based immunosuppression is safe and effective to treat recurrent focal segmental glomerulosclerosis after pediatric kidney transplantation. Clin Transplant 27(2):E143-E150

46. Raafat R, Travis LB, Kalia A, Diven S (2000) Role of transplant induction therapy on recurrence rate of focal segmental glomerulosclerosis. Pediatr Nephrol 14:189-194

47. Cheong HI, Han HW, Park HW, Ha IS, Han KS, Lee HS, Kim SJ, Choi Y (2000) Early recurrent nephrotic syndrome after renal transplantation in children with focal segmental glomerulosclerosis. Nephrol Dial Transplant 15:78-81

48. Greenstein SM, Delrio M, Ong E, Feuerstein D, Schechner R, Kim D, Corey H, Kaskel R, Tellis VA, Moritz ML (2000) Plasmapheresis treatment for recurrent focal sclerosis in pediatric renal allografts. Pediatr Nephrol 14:1061-1065

49. Matalon A, Markowitz GS, Joseph RE, Cohen DJ, Saal SD, Kaplan B, D'Agati VD, Appel GB (2001) Plasmapheresis treatment of recurrent FSGS in adult renal transplant recipients. Clin Nephrol 56(4): 271-278

50. Ohta T, Kawaguchi H, Hattori M, Komatsu Y, Akioka Y, Nagata M, Shiraga H, Ito K, Takahashi K, Ishikawa N, Tanabe K, Yamaguchi Y, Ota K (2001) Effect of pre- and postoperative plasmapheresis on posttransplant recurrence of focal segmental glomerulosclerosis in children. Transplantation 71(5):628-633

51. Pradhan M, Petro J, Palmer J, Meyers K, Baluarte HJ (2003) Early use of plasmapheresis for recurrent post-transplant FSGS. Pediatr Nephrol 18:934-938
52. Deepens JK, Andresdottir MB, Croockewit S, Wetzels JF (2004) Plasma exchange improves graft survival in patients with recurrent focal glomerulosclerosis after renal transplant. Transpl Int 17(3):151157

53. Otsubo S, Tanabe K, Shinmura H, Ishikawa N, Tokumoto T, Hattori M, Ito K, Nitta K, Akiba T, Nihei H, Toma H (2004) Effect of posttransplant double filtration plasmapheresis on recurrent focal and segmental glomerulosclerosis in renal transplant recipients. Ther Apher Dial 8(4):299-304

54. Hubsch H, Montane B, Abitbol C, Chandar J, Shariatmadar S, Ciancio G, Burke G, Miller J, Strauss J, Zilleruelo G (2005) Recurrent focal glomerulosclerosis in pediatric renal allografts: the Miami experience. Pediatr Nephrol 20:210-216

55. Garcia CD, Bittencourt VB, Tumelero A, Antonello JS, Malheiros D, Garcia VD (2006) Plasmapheresis for recurrent posttransplant focal segmental glomerulosclerosis. Transplant Proc 38(6):1904-1905

56. Pardon A, Audard V, Caillard S, Moulin B, Desvaux D, Bentaarit B, Remy P, Sahali D, Roudot-Thoraval F, Lang P, Grimbert P (2006) Risk factors and outcome of focal and segmental glomerulosclerosis recurrence in adult renal transplant recipients. Nephrol Dial Transplant 21(4):1053-1059

57. Fuentes GM, Meseguer CG, Carrion AP, Hijosa MM, Garcia-Pose A, Melgar AA, Torres MN (2010) Long-term outcome of focal segmental glomerulosclerosis after pediatric renal transplantation. Pediatr Nephrol 25(3):529-534

58. Gungor O, Sen S, Kircelli F, Yilmaz M, Sarsik B, Ozkahya M, Hoscoskun C, Ok E, Toz H (2011) Plasmapheresis therapy in renal transplant patients: five-year experience. Transplant Proc 43(3):853857

59. Gonzalez E, Ettenger R, Rianthavorn P, Tsai E, Malekzadeh M (2011) Preemptive plasmapheresis and recurrence of focal segmental glomerulosclerosis in pediatric renal transplantation. Pediatr Transplant 15(5):495-501

60. Straatmann C, Kallash M, Killackey M, Iorember F, Aviles D, Bamgbola O, Carson T, Florman S, Vehaskari MV (2014) Success with plasmapheresis treatment for recurrent focal segmental glomerulosclerosis in pediatric renal transplant recipients. Pediatr Transplant 18(1):29-34

61. Hattori M, Chikamoto H, Akioka Y, Nakakura H, Ogino D, Matsunaga A, Fukazawa A, Miyakawa S, Khono M, Kawaguchi H, Ito K (2003) A combined low-density lipoprotein apheresis and prednisone therapy for steroid-resistant primary focal segmental glomerulosclerosis in children. Am J Kidney Dis 42(6):1121-1130

62. Benz K, Dotsch J, Rascher W, Stachel D (2004) Change of the course of steroid-dependent nephrotic syndrome after rituximab therapy. Pediatr Nephrol 19(7):794-797

63. Nozu K, Iijima K, Fujisawa M, Nakagawa A, Yoshikawa N, Matsuo M (2005) Rituximab Treatment for Posttransplant Lymphoproliferative Disorder (PTLD) induces complete remission of recurrent nephrotic syndrome. Pediatr Nephrol 20(11):1660-1663

64. Pescovitz MD, Book BK, Sidner RA (2006) Resolution of recurrent focal segmental glomerulosclerosis proteinuria after rituximab treatment. N Engl J Med 354(18):1961-1963

65. Hristea D, Hadaya K, Marangon N, Buhler L, Villard J, Morel P, Martin PY (2007) Successful treatment of recurrent focal segmental glomerulosclerosis after kidney transplantation by plasmapheresis and rituximab. Transpl Int 20(1):102-105

66. Kamar N, Faguer S, Esposito L, Guitard J, Nogier MB, Durand D, Rostaing L (2007) Treatment of focal segmental glomerulosclerosis with rituximab: 2 case reports. Clin Nephrol 67(4):250-254

67. Grossmann J, Scheuermann EH, Porubsky S, Kachel HG, Geiger H, Hauser IA (2007) Abrogation of nephrotic proteinuria by rituximab treatment in a renal transplant patient with relapsed focal segmental glomerulosclerosis. Transpl Int 20(6):558-562

68. Meyer TN, Thaiss F, Stahl RA (2007) Immunoadsorbtion and rituximab therapy in a second living-related kidney transplant patient with 
recurrent focal segmental glomerulosclerosis. Transpl Int 20(12): 1066-1071

69. El-Firjani A, Hoar S, Karpinski J, Bell R, Deschenes MJ, Knoll GA (2008) Post-transplant focal segmental glomerulosclerosis refractory to plasmapheresis and rituximab therapy. Nephrol Dial Transplant 23(1):425

70. Yabu JM, Ho B, Scandling JD, Vincenti F (2008) Rituximab failed to improve nephrotic syndrome in renal transplant patients with recurrent focal segmental glomerulosclerosis. Am J Transplant 8:222-227

71. Shimizu M, Kitagawa K, Nishio S, Yokoyama T, Furuichi K, Ohta K, Wada T, Yachie A (2010) Successful treatment of recurrent focal segmental glomerulosclerosis after renal transplantation by lymphocytapheresis and rituximab. Transpl Int 9:e53-e55

72. Grenda R, Jarmuzek W, Piatosa B, Rubik J (2011) Long-term effect of rituximab in maintaining remission of recurrent and plasmapheresis-dependent nephrotic syndrome post-renal transplantation - case report. Pediatr Transplant 2(6):e121-e125

73. Sethna C, Benchimol C, Hotchkiss H, Frank R, Infante L, Vento S, Trachtman H (2011) Treatment of recurrent focal segmental glomerulosclerosis in pediatric kidney transplant recipients: effect of rituximab. J Transplant 389542. doi:10.1155/2011/389542

74. Tsagalis G, Psimenou E, Nakopolou L, Laggouranis A (2011) Combination treatment with plasmapheresis and rituximab for recurrent focal segmental glomerulosclerosis after renal transplantation. Artif Organs 35(4):420-425

75. Okamoto M, Koshino K, Sakai K, Nobori S, Matsuyama M, Ushigome H, Okajima H, Masuzawa N, Yoshimura N (2011) A case of recurrent Focal Segmental Glomerulosclerosis (FSGS) involving massive proteinuria ( $>50 \mathrm{~g} /$ day) immediately after renal transplantation. Clin Transplant Suppl 23:53-58

76. Stewart ZA, Shetty R, Nair R, Reed AI, Broohy PD (2011) Case report: successful treatment of recurrent focal segmental glomerulosclerosis with a novel rituximab regimen. Transplant Proc 43(10):3994-3996

77. Audard V, Kamar N, Sahali D, Cardeau-Desangles I, Homs S, Remy P, Aouizerate J, Matignon M, Rostaing L, Lang P, Grimbert P (2012) Rituximab therapy prevents focal and segmental glomerulosclerosis recurrence after a second renal transplantation. Transpl Int 5:e62-e66

78. Kumasi J, Shatat IF, Skversky AL, Woroniecki RP, Del Rio M, Perelstein EM, Johnson VL, Mahesh S (2013) Rituximab in posttransplant pediatric recurrent focal segmental glomerulosclerosis. Pediatr Nephrol 28(2):333-338

79. Fornoni A, Sageshima J, Wei C, Merscher-Gomez S, Aguillon-Prada R, Jauregui AN, Li J, Mattiazzi A, Ciancio G, Chen L, Zilleruelo G, Abitbol C, Chandar J, Seeherunvong W, Ricordi C, Ikehata M, Rastaldi MP, Reiser J, Burke GW 3rd (2011) Rituximab targets podocytes in recurrent focal segmental glomerulosclerosis. Sci Transl Med 3(85):85ra46

80. Cho JH, Lee JH, Park GY, Lim JH, Kim JS, Kang YJ, Kwon O, Choi JY, Park SH, Kim YL, Kim HK, Huh S, Kim CD (2014) Successful treatment of recurrent focal segmental glomerulosclerosis with a lowdose rituximab in a kidney transplant recipient. Ren Fail 36(4):623626

81. Yu CC, Fornoni A, Weins A, Hakroush S, Maiguel D, Sageshima J, Chen L, Ciancio G, Faridi MH, Behr D, Campbell KN, Chang JM, Chen HC, Oh J, Faul C, Arnaout MA, Fiorina P, Gupta V, Greka A, Burke GW 3rd, Mundel P (2013) Abatacept in B7-1-positive proteinuric kidney disease. N Engl J Med 369(25):2416-2423

82. Garin EH, Reiser J, Cara-Fuentes G, Wei C, Matar D, Wang H, Alachkar N, Johnson RJ (2014) Case series: CTLA4-IgG1 therapy in minimal change disease and focal segmental glomerulosclerosis. Pediatr Nephrol. doi:10.1007/s00467-014-2957-6

83. Belingheri M, Lazzari L, Parazzi V, Groppali E, Biagi E, Gaipa G, Giordano R, Rastaldi MP, Croci D, Biondi A, Rebulla P, Edefonti A, Ghio L (2013) Allogeneic mesenchymal stem cell infusion for the stabilization of focal segmental glomerulosclerosis. Biologicals 41(6):439-445

84. Vanikar AV, Trivedi HL, Shah PR, Kanodia KV, Patel RD, Modi PR, Dave SD, Singhai AM, Shah VR, Trivedi VB, Shankar V (2013) Single-center experience on renal transplantation in primary focal and segmental glomerulosclerosis using hematopoietic stem cell transplantation in thymus, bone marrow, portal and peripheral circulation. Saudi J Kidney Dis Transpl 24(1):15-21

85. Suthanthiran M, Schwartz JE, Ding R, Abecassis M, Dadhania D, Samstein B, Knechtle SJ, Friedewald J, Becker YT, Sharma VK, Williams NM, Chang CS, Hoang C, Muthukumar T, August P, Keslar KS, Fairchild RL, Hricik DE, Heeger PS, Han L, Liu J, Riggs M, Ikle DN, Bridges ND, Shaked A (2013) Clinical Trials in Organ Transplantation 04 (CTOT-04) Study Investigators. Urinarycell mRNA profile and acute cellular rejection in kidney allografts. $\mathrm{N}$ Engl J Med 369(1):20-31

86. Beaudreuil S, Zhang X, Kriaa F, Dantal J, Francois H, Vazquez A, Charpentier B, Lorenzo HK, Durrbach A (2014) Protein A immunoadsorption cannot significantly remove the soluble receptor of urokinase from sera of patients with recurrent focal segmental glomerulosclerosis. Nephrol Dial Transplant 29(2):458-463

\section{Answers:}

\section{Correct answer: a}

Only young age and no other clinical or immunological markers have been associated with a higher risk of recurrent FSGS.

2. Correct answer: a

Primary steroid resistance is suggestive of a genetic cause of FSGS and is associated with a lower risk of recurrent FSGS. In contrast, initial steroid responsiveness that evolves into late steroid resistance is indicative of a potential immune-mediated mechanism of disease that is associated with a higher risk of recurrent disease. The response pattern to other drugs is not useful in predicting recurrent FSGS post-transplantation.

3. Correct answer: c

The gold standard for diagnosis of recurrent FSGS is renal biopsy. The epidemiology of recurrent FSGS is difficult to ascertain, and may be over or underestimated, given that biopsies are often not performed. Patients often do not have baseline biopsies, and so differentiating between de novo FSGS and recurrent FSGS can be very difficult. Adding to the problem, biopsies can be challenging to interpret, as patients can have more than one type of pathology at the same time.

4. Correct answer: $\mathrm{d}$

Podocyte expression of SMPDL-3b has been shown to be a target for rituximab and correlates with a clinical response, namely reduction in proteinuria. CD20 is expressed on VB cell and has not been linked to efficacy of the antibody in patients with recurrent FSGS. Podocin is an important genetic cause of FSGS but its expression is not effected by rituximab. B7.1 is the target of abatacept treatment and does not bind rituximab 